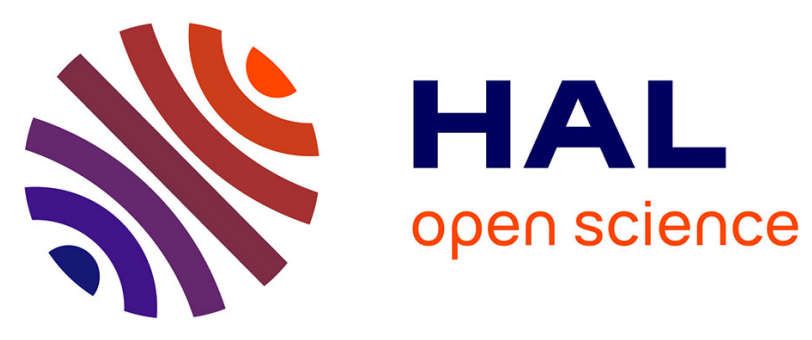

\title{
Branching effect on the linear and nonlinear optical properties of styrylpyrimidines
}

Fotis Kournoutas, Arnaud Fihey, Jean-Pierre Malval, Arnaud Spangenberg, Michaela Fecková, Pascal Le Poul, Claudine Katan, Françoise Robin Le Guen, Filip Bureš, Sylvain Achelle, et al.

\section{To cite this version:}

Fotis Kournoutas, Arnaud Fihey, Jean-Pierre Malval, Arnaud Spangenberg, Michaela Fecková, et al.. Branching effect on the linear and nonlinear optical properties of styrylpyrimidines. Physical Chemistry Chemical Physics, 2020, 22 (7), pp.4165-4176. 10.1039/C9CP06476A . hal-02464600

\section{HAL Id: hal-02464600 \\ https://hal-univ-rennes1.archives-ouvertes.fr/hal-02464600}

Submitted on 12 May 2020

HAL is a multi-disciplinary open access archive for the deposit and dissemination of scientific research documents, whether they are published or not. The documents may come from teaching and research institutions in France or abroad, or from public or private research centers.
L'archive ouverte pluridisciplinaire HAL, est destinée au dépôt et à la diffusion de documents scientifiques de niveau recherche, publiés ou non, émanant des établissements d'enseignement et de recherche français ou étrangers, des laboratoires publics ou privés. 


\title{
Branching effect on the linear and nonlinear optical properties of styrylpyrimidines
}

Fotis Kournoutas, ${ }^{\mathrm{a}}$ Arnaud Fihey, ${ }^{\mathrm{b}}$ Jean-Pierre Malval, ${ }^{\mathrm{c}}$ Arnaud Spangenberg, ${ }^{\mathrm{c}}$ Michaela Fecková,,d Pascal le Poul, ${ }^{\text {b }}$ Claudine Katan, ${ }^{\text {b, }}$ Françoise Robin-le Guen, ${ }^{b}$ Filip Bureš, ${ }^{\text {d }}$ Sylvain Achelle ${ }^{\mathrm{b}, *}$, Mihalis Fakis, ${ }^{\mathrm{a}, *}$

${ }^{a}$ Department of Physics, University of Patras, Greece, GR-26504 Patras, Greece. E mail: fakis@upatras.gr

bUniv Rennes, CNRS, ISCR (Institut des Sciences Chimiques de Rennes) - UMR 6226, F 35000 Rennes, France. E mails: claudine.katan@univ-renes1.fr; sylvain.achelle@univrennes1.fr

${ }^{\mathrm{c}}$ Institut de Science des Matériaux de Mulhouse CNRS-UMR 7361, Université de Haute Alsace, 15 rue Jean Starcky, 68057, Mulhouse, France.

${ }^{\mathrm{d}}$ Institute of Organic Chemistry and Technology, Faculty of Chemical Technology, University of Pardubice, Studenská 573, Pardubice 53210, Czech Republic.

\begin{abstract}
This contribution aims at investigating the branching effect on the steady state, time resolved fluorescence and two-photon absorption (2PA) properties of dimethylamino and diphenylamino substituted styrylpyrimidine derivatives, by means of a combined experimental and theoretical study. In contrast to classical branched molecules with a triphenylamine central core and electron accepting groups at the periphery, here, branched molecules with the reverse topology and different symmetry are examined, namely a styrylpyrimidine group is used as the electron withdrawing core and dimethylamino or diphenylamino donors are incorporated at the periphery. Besides, compared to the great
\end{abstract}


majority of existing branched systems, the herein studied molecules do not have the $C_{3}$ symmetry. For that reason, the spectral region of the linear and non-linear optical spectra of the two and three branched chromophores remains actually similar. Interestingly, whereas the one-photon absorption spectra of the one-branched systems versus the two- or three-branched ones are spectrally shifted, there is almost no spectral shift for the main 2PA spectral region. Meanwhile, there is still an enhancement of both linear and nonlinear optical responses. Overall, here we developed a strategy that enhances the 2PA response while maintaining the spectral position. Specifically, 2PA cross section values as high as 500 GM have been obtained for the diphenylamino A- $(\pi-\mathrm{D})_{3}$ molecule in dichloromethane.

\section{Introduction}

Among numerous organic chromophores with interesting and promising optical properties for potential applications in optoelectronics, styrylpyrimidine chromophores have been the subject of intense research during the past two decades. ${ }^{1}$ Due to the electron-deficient character of the pyrimidine heterocycle, pyrimidinyl fragments can be used as electronwithdrawing groups in push-pull structures. ${ }^{1,2}$ Styrylpyrimidines substituted by electrondonating fragments exhibit therefore significant intramolecular charge transfer (ICT). ${ }^{1}$ As initially described by Pascal et al. ${ }^{3}$ 4-styrylpyrimidines and 4,6-distyrylpyrimidines have been extensively used as fluorophores ${ }^{4}$ and their luminescence properties can be easily tuned by protonation, ${ }^{4 \mathrm{a}-\mathrm{e}, 5}$ complexation with various metal cations $^{6}$ or the polarity of the media. ${ }^{4 \mathrm{a}-\mathrm{e}}$ Recently, some of us have designed a series of 2,4,6-tristryrylpyrimidine derivatives and the effect of protonation on the emission properties has been studied. ${ }^{7}$ In general, the protonation or the complexation of pyrimidine push-pull chromophores leads to the generation of a novel red-shifted charge transfer absorption band. The protonation also induces either a quenching of emission or in some cases a new red-shifted emission band due to the protonated species. ${ }^{8}$ Recently, white light emission originated by a mixture of neutral and protonated push-pull 
pyrimidine chromophores has been reported. ${ }^{9}$ Styrylpyrimidines have been also described as $2^{\text {nd }}$ order nonlinear optical (NLO) chromophores ${ }^{4 \mathrm{~b}, 10}$ and as two-photon absorption (2PA) chromophores. ${ }^{10 \mathrm{~d}, 11}$ In particular, the 4,6-distyrylpyrimidines are now well established as 2PA chromophores for biological imaging, ${ }^{12} 3 \mathrm{D}$ data storage ${ }^{13}$ and microfabrication. ${ }^{14}$

It has been demonstrated that the branching effect going from dipolar (D- $\pi-A)$, to quadrupolar (D- $(\pi-A)_{2}$ and $\left.A-(\pi-D)_{2}\right)$ and octupolar $\left(D-(\pi-A)_{3}\right.$ and $\left.A-(\pi-D)_{3}\right)$ structures can have a significant influence on the linear and nonlinear optical properties of chromophores. ${ }^{15}$ In particular, a significant enhancement of 2PA properties has been observed in triphenylamine (TPA) based octupolar systems and other structures, due to a coherent coupling between the branches. ${ }^{15 g}$ A significant increase of the 2PA cross section figure of merit has been also reported for quadrupolar 4,6-distyrylpyrimidine structures. ${ }^{10 \mathrm{~d}, 12 \mathrm{~d}-\mathrm{e}, 13}$ Apart from the enhancement of the NLO properties, octupolar systems have attracted significant research interest due to their increased energy harvesting ability and the capability for coherent and/or incoherent energy transfer among the branches. However, in contrast to the most common octupolar topology D-( $\pi-\mathrm{A})_{3}$, where an electron donating core (e.g. TPA) is substituted with $\pi$-conjugated linkages and electron accepting groups at the periphery, the reverse topology A$(\pi-D)_{3}$, having an electron withdrawing core and electron donors at the periphery, is scarce, ${ }^{16}$ even more with central core without C3 symmetry, and deserves to be pursued and taken further.

In this work, we report on the linear and non-linear optical properties of styrylpyrimidine branched chromophores of the A-( $\pi-\mathrm{D})_{\mathrm{n}}(n=1,2,3)$ structure. Styrylpyrimidine is used as an electron withdrawing core (A), while dimethylamino or diphenylamine groups are used as electron donors (D) at the periphery. Steady state spectroscopy, fs to ns time resolved spectroscopy and two-photon induced fluorescence spectroscopy have been used along with 
TD-DFT calculations. The properties of the styrylpyrimidines are discussed addressing the effect of branching, symmetry, solvent polarity and electron donor change.

\section{Experimental}

Materials. The chemical structures of the herein studied compounds 1a-c and 2a-c are shown in Chart 1. At first sight, these compounds can be thought as dipolar, quadrupolar and octupolar in nature, bearing dimethylamino or diphenylamino electron donating substituents and pyrimidine electron acceptor as well as olefinic $\pi$-bridges. The synthesis and chemical characterization of these compounds were described previously. ${ }^{4 a, 4 b, 7}$
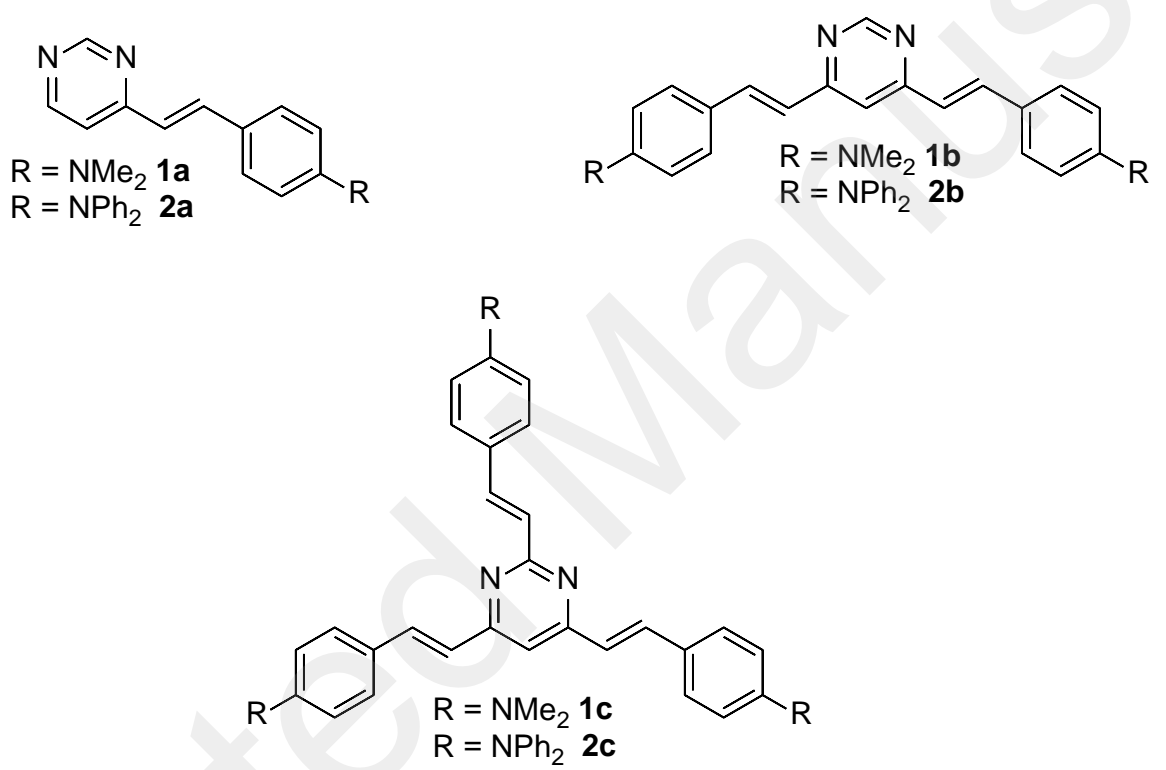

Chart 1: Structures of the styrylpyrimidine branched chromophores

Steady state spectroscopy. The absorption and fluorescence spectra of the samples in solutions were measured using a Jasco V-650 UV-Vis and a Horiba Fluoromax spectrophotometer respectively. For the fluorescence quantum yields (Ф) calculation, 9,10bis(phenylethynyl)anthracene in cyclohexane was used as standard $(\Phi=1.00)$.

Time resolved spectroscopy in the fs-ps and ps-ns timescale. For time resolved fluorescence measurements in the fs-ps timescale, a femtosecond time resolved upconversion (FU) system has been used. ${ }^{17}$ A Ti:Sapphire femtosecond laser (80 fs pulse duration, $80 \mathrm{MHz}$ 
repetition frequency) is used as the laser source while the samples have been excited by its second harmonic at $400 \mathrm{~nm}(<2 \mathrm{~mW})$. The Instrument's Response Function (IRF) was 250 fs. Both magic angle and anisotropy dynamics have been detected.

For time resolved fluorescence measurements in the ps-ns timescale, the Time Correlated Single Photon Counting (TCSPC) technique has been used, based on a Fluotime 200 spectrometer (Picoquant). ${ }^{18}$ The excitation source was a ps diode laser emitting 60 ps pulses at $400 \mathrm{~nm}$ and the IRF was $\sim 80$ ps. The samples for fluorescence dynamics measurements were dilute solutions with optical density (O.D.) at the excitation wavelength of $\sim 0.1$.

Two-photon absorption. The 2PA measurements were performed with femtosecond modelocked laser pulses using a Ti: Sapphire laser (Coherent, Chameleon Ultra II: pulse duration: 140 fs; repetition rate: $80 \mathrm{MHz}$; wavelength range: 680-1040 nm). A two-photon excited fluorescence method $^{19}$ was employed to measure the 2PA cross-sections, $\delta$. The measurements of 2PA cross-sections were performed relative to reference molecules $(r)$ such as fluorescein ${ }^{19,20}$ in water at $\mathrm{pH}=11$. The samples used for the 2PA characterization were $10^{-5}-10^{-4} \mathrm{M}$ solutions in $\mathrm{CH}_{2} \mathrm{Cl}_{2}$. The values of $\delta$ for a sample (s) is given by:

$$
\delta_{S}=\frac{S_{S} \Phi_{r} \eta_{r} c_{r}}{S_{r} \Phi_{S} \eta_{S} c_{S}} \cdot \delta_{r}
$$

Where $S$ is the detected two-photon excited fluorescence integral area, $c$ is the concentration of the chromophores, $\Phi$ is the fluorescence quantum yield of the chromophores and $\eta$ is the collection efficiency of the experimental set-up which accounts for the wavelength dependence of the detectors and optics as well as the difference in refractive indices between the solvents in which the reference and sample compounds are dissolved. The measurements were conducted in a regime where the fluorescence signal showed a quadratic dependence on the intensity of the excitation beam, as expected for two-photon induced emission. For the calibration of the 2PA spectra, the two-photon excited fluorescence signal of each compound 
was recorded at the same excitation wavelength as that used for standards (i.e. $\lambda_{\text {exc }}=782 \mathrm{~nm}$ for fluorescein). The laser intensity was in the range of $0.2-2 \times 10^{9} \mathrm{~W} / \mathrm{cm}^{2}$. The experimental error on the reported cross section is $15 \%$.

\section{Calculations}

We used density functional theory (DFT) and time-dependent (TD) DFT approaches, as implemented in the Gaussian 16 package, ${ }^{21}$ to model all chromophores of interest. All calculations have been performed in vacuum (gas phase) to provide general insights regardless of the solvent used, and consist of:

- Molecular structure optimisations, using the PBE0 hybrid functional ${ }^{22}$ combined with the 6-31G(d,p) basis set, followed by frequency calculations to identify the nature of the energy minimum as a global minimum.

- Linear optical properties computation, using the range-separated hybrid functional CAM-B3LYP alongside a 6-31G(d,p) basis set. ${ }^{23}$ The absorption features are obtained through the first 15 vertical excitations, and the emission energies by optimizing the geometry of the first excited-state, which is then validated by an excited-state frequency calculation. The excitation and emission energies are convoluted into UVVis bands by applying Gaussian functions with a Half-width at Half-Height of $0.3 \mathrm{eV}$.

- 2PA spectra (Figure S9) were obtained employing the density matrix formalism for non-linear optical responses as proposed by S. Tretiak and V. Chernyak, ${ }^{24,25}$ using the Gaussian 03 suite at the B3LYP/6-31G(d) level of theory including up to 20 singlet ES. This level of theory has been shown to provide good qualitative information for structure-TPA relationships. ${ }^{25}$ The damping factor introduced to simulate the finite linewidth in the resonant spectra has been fixed to $\Gamma=0.18 \mathrm{eV} \cdot{ }^{25}$ The Geometries of the molecules used in these calculations are those obtained at the PBE0/6-31G(d,p) level. 
We also used a two-state model ${ }^{25}$ to provide further qualitative information (Table S12).

For comments on the choice of the functional/basis-set to explore the optical properties, see the Supporting Information.

\section{Results and discussion}

\section{Molecular structure}

Ground and excited state geometry optimizations, performed in vacuum, for the chromophores of interest lead to planar molecular backbones, except for the terminal diphenylamino of series 2 members, which show the well-known propeller-shape with dihedral angles of c.a. $40^{\circ} .{ }^{15 g}$ For the two and three-branched compounds, we investigated two and three different molecular conformations (Figure S1). Computed Gibbs free energies show that the most linear ones, having two branches almost parallel to the $\mathrm{N}-\mathrm{N}$ axis of the pyrimidine ring, are a few $\mathrm{kcal} / \mathrm{mol}$ more stable than the other conformers, leading to Boltzmann population ratio above $80 \%$. Therefore, we will focus on the latter, bearing in mind that it is most likely that the various conformations coexist in solution and contribute to the broadening of the optical spectra. The planar geometries with lowest energy for the most linear ones are favored because of reduced steric hindrance afforded by the central pyrimidine ring as compared for instance with the TPA one. ${ }^{15 \mathrm{~g}}$

For both dipolar monomeric compounds $\mathbf{1 a}$ and $\mathbf{2 a}$, in moving from ground to excited state geometries, the bond length alternation (BLA) of the vinylene moiety gets reduced but nevertheless not reversed (Table S1). For the two-branched chromophores $\mathbf{1 b}$ and $\mathbf{2 b}$, a similar phenomenon is observed and the mirror plane (perpendicular to the $\mathrm{N}-\mathrm{N}$ axis) found for the ground state molecular geometries is maintained in the relaxed excited state. The latter is consistent with conditional bistability and we anticipate that $\mathbf{1} \mathbf{b}$ and $\mathbf{2} \mathbf{b}$ belong to class I as 
defined by Terenziani and coworkers with localization of the excitation on one of the two branches in polar solvents. ${ }^{26}$ Contrarily, for the three-branched chromophores 1c and 2c, excited state geometry optimization leads to symmetry breaking reminiscent from the multistable potential energy surface found in related octupolar chromophores. ${ }^{27}$ In fact, even in vacuum, the two equivalent branches (position C4 and C6) undergo different structural relaxation with a slightly larger BLA (Table S1) on one of these two branches and, besides, a slight increase of the BLA on the third branch (position C2).

\section{Optical properties in non-polar solvents}

Computed optical spectra in vacuum are reported in Figures 1 and S2 for compounds 2a-c and 1a-c, respectively. As expected, the diphenylamino substituted styryl pyrimidines show systematic red-shifted bands as compared to their dimethylamino analogues, which is also evident from experimental data (Figure 2). Absorption properties of both series reveal the same trend with $\lambda_{\text {abs }}(\mathbf{a})<\lambda_{\text {abs }}(\mathbf{c})<\lambda_{\text {abs }}(\mathbf{b})$. This is further consistent with experimental data (Figure 2 and Table S2) obtained in non-polar solvents, namely $n$-hexane (n-HEX) and toluene (TOL). From other series of branched chromophores as well as a direct consequence of increasing molecular size, one would have expected a progressive red shift with increasing number of branches. The fact that this is not observed is a direct consequence of a lack of $\mathrm{C}_{3}$ symmetry of the pyrimidine core, the latter bearing two equivalent positions for functionalization in C4 and C6 that differs from the third in C2. Inspection of transition densities (Figure 1 and S2) and computed transition energies (Table S3) reveals that the lowest excitation of the two and three branched chromophores are almost identical, with similar weight on the two branches grafted at C4 and C6 and the same transition energy. In the three-branched compounds $\mathbf{1 c}$ and $\mathbf{2 c}$, the lowest excitation is not doubly degenerated due to the lack of 3-fold symmetry (Table S3), and the second excitation bearing significant 
oscillator strength shows up about $0.2 \mathrm{eV}$ higher in energy and is responsible for the blue shifted absorption band. Noteworthy, the computed second (third) excitation of the two(three-) branched chromophores bear significantly smaller oscillator strength and are anticipated to contribute most effectively to the 2PA cross sections (vide infra). This is consistent with experimental data where, for compounds $\mathbf{1} \mathbf{b}$ and $\mathbf{2} \mathbf{b}$, a broadening of the absorption spectra is observed due to the splitting of the excited state which is qualitatively predicted by the Frenkel exciton model. ${ }^{15 g, 28}$ Specifically, in V-shaped molecules, both lower and higher energy states are one-photon allowed. This broadening is more obvious in $\mathbf{1 b}$ where a high-energy shoulder typical for quadrupolar molecules is slightly observed in the apolar solvents $n$-hexane ( $n$-HEX) and toluene (TOL) (at 370 and $385 \mathrm{~nm}$ respectively).
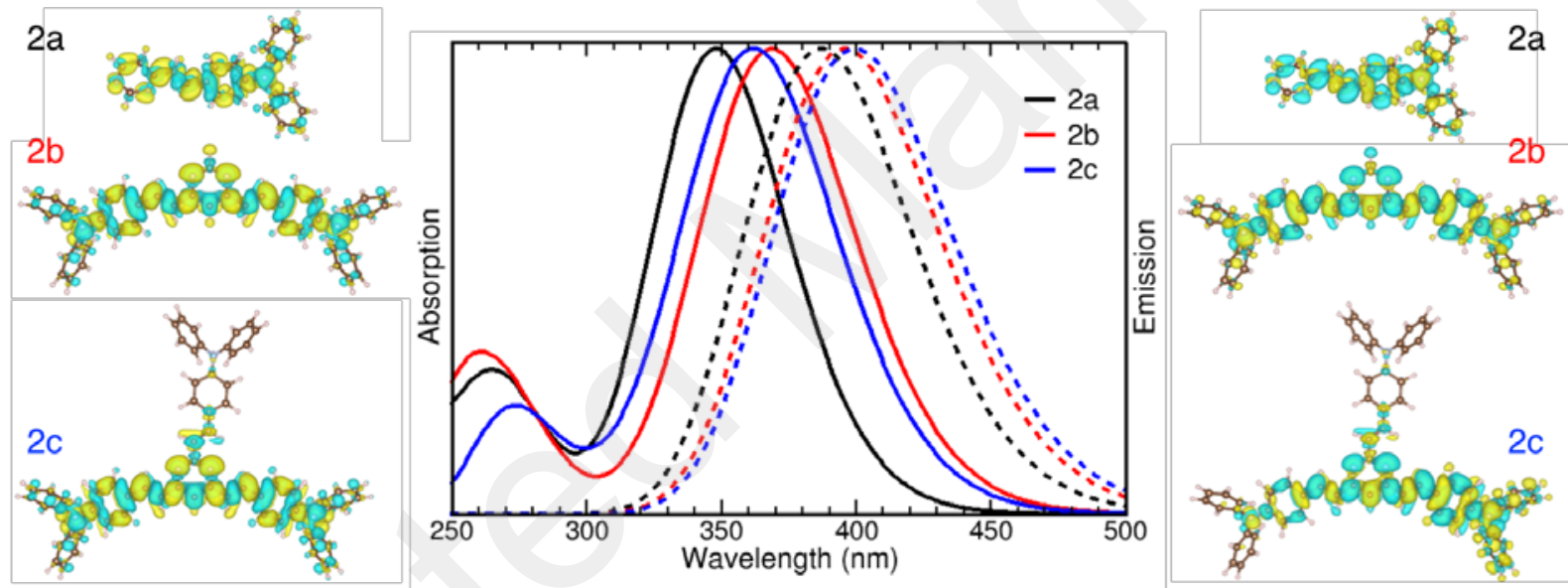

Figure 1. Computed optical properties of 2a-c in vacuum (For 1a-c see Figure S2). The central panel shows normalized absorption (full lines) and emission (dashed lines) spectra. Transition densities of the lowest lying excited state relevant to absorption and emission are depicted on the left and right sides, respectively.

Computed emission spectra in gas phase are also consistent with experimental ones in n-Hex

(Figure 2) with: i) bands slightly red-shifted for the branched chromophores as compared to the dipolar monomers, ii) almost identical emission spectra for $\mathbf{1 b}$ and $\mathbf{1 c}$ as a result of comparable electronic redistribution localized on the branches in position C4 and C6 (Figure S2) and iii) a slight red-shift of $\mathbf{2} \mathbf{c}$ as compared to $\mathbf{2} \mathbf{b}$ and distinguishable symmetry breaking visible in the transition density of $\mathbf{2 c}$ (Figure 1). 


\section{Solvatochromism from steady state spectroscopy}

Figure 2 further reports on the solvatochromic behavior of steady state absorption and fluorescence using various solvents with increasing polarity, namely $n$-HEX, TOL, tetrahydrofuran (THF), chloroform $\left(\mathrm{CHCl}_{3}\right)$, dichloromethane $\left(\mathrm{CH}_{2} \mathrm{Cl}_{2}\right)$, acetone (ACT) and acetonitrile (ACN). The photophysical data for all compounds in $\mathrm{CH}_{2} \mathrm{Cl}_{2}$ are summarized in Table 1 while the corresponding data in all solvents are summarized in Table S2.


Figure 2. Normalized experimental absorption and fluorescence spectra of 1a-c and 2a-c in various solvents.

Changing the solvent polarity does not significantly affect the absorption spectra. In all cases, the compounds in series $\mathbf{1}$ bearing the dimethylamino donors, show blue-shifted absorption and fluorescence spectra in all solvents compared to the compounds in series $\mathbf{2}$. Increasing the number of branches from $\mathbf{1 a}$ and $\mathbf{2 a}$ to $\mathbf{1 b}$ and $\mathbf{2} \mathbf{b}$, results in a red-shift of the spectra indicating an interaction among the branches. ${ }^{15 a}$ In the octupolar-like compounds, a blue shift of the absorption peak with respect to the quadrupolar-like ones, is obtained. Furthermore, as expected, the molar extinction coefficients, $\epsilon$, increase with the number of branches (Table 1). Finally, the transition dipole moments of absorption, $\mu_{a b s}$, were calculated by using the 
formulation described in the SI, while the results are summarized in Table 1 . Similarly to the $\epsilon$ values, $\mu_{a b s}$ increases with branching number, being 10.3 and $9.3 \mathrm{D}$ for 1c and 2c respectively, which is in line with increasing computed oscillator strength of the compounds in gas phase (Table S3).

Table 1. Photophysical data of the molecules 1a-c and 2a-c in $\mathrm{CH}_{2} \mathrm{Cl}_{2}$.

\begin{tabular}{ccccccc} 
Sample & $\lambda_{\text {abs }}(\mathrm{nm})$ & $\lambda_{\text {em }}(\mathrm{nm})$ & $\epsilon\left(\mathrm{M}^{-1} \mathrm{~cm}^{-1}\right)$ & $\Phi$ & $\mu_{a b s}(D)$ & $\mu_{\text {em }}(D)$ \\
1a & 392 & 493 & 28600 & 0.15 & 7.41 & - \\
2a & 399 & 531 & 32000 & 0.45 & 5.57 & 6.07 \\
1b & 426 & 526 & 43900 & 0.40 & 8.31 & 7.02 \\
2b & 430 & 538 & 47900 & 0.55 & 9.07 & 7.03 \\
$\mathbf{1 c}$ & 403 & 519 & 53800 & 0.22 & 10.3 & 7.46 \\
2c & 415 & 531 & 59300 & 0.56 & 9.27 & 6.76 \\
\hline
\end{tabular}

All compounds exhibit significant fluorescence solvatochromism with a red-shift of the fluorescence peaks reaching $150 \mathrm{~nm}$ by increasing the solvent polarity from n-HEX to ACN. The fluorescence spectra are narrow and structured in apolar solvents while, as expected for polar molecules, they become broad and featureless in polar media. Significant positive solvatochromism is expected for linear dipolar compounds with enhanced excited state dipole moments due to their D- $\pi$-A nature. On the other hand, in quadrupolar and octupolar molecules, the significant positive solvatochromism originates from a symmetry breaking of the excited state, which is conditional in our V-shaped chromophores and unconditional in the 3-branched chromophores (vide supra). ${ }^{27,29}$ Thus, prior to emission, the excitation becomes mainly localized on a single chromophoric unit rendering the excited state polar. As a result of the pyrimidine core, the solvatochromic shift is larger for the branched chromophores as compared to its dipolar analogue, revealing the distinctive nature of the underlying excited states.

The emission transition dipole moments, $\mu_{e m}$, have also been calculated for $\mathbf{1 b}, \mathbf{1 c}$ and $\mathbf{2 a - 2 \mathbf { c }}$ compounds in $\mathrm{CH}_{2} \mathrm{Cl}_{2}$ (see the SI for the methodology). Calculations were not performed for 1a, because of the fast excited state decay of this molecule which is within the resolution of 
our ns time resolved technique (vide infra) and therefore suffers from uncertainty. $\mu_{e m}$ becomes higher by increasing the branching number from $\mathbf{1 b}$ to $\mathbf{1 c}$ and from $\mathbf{2 a}$ to $\mathbf{2 b}$ indicating a delocalized emitting state. However, in $\mathbf{2 c}, \mu_{e m}$ decreases compared to $\mathbf{2 b}$ which means that the emitting state is localized on a smaller chromophoric unit pointing to a loss of symmetry.

The dependence of the fluorescence peak on the frequency polarizability of the solvents $f(\varepsilon)=(\varepsilon-1) /(2 \varepsilon+1)$ is shown in Figure S3. The dielectric constants $(\varepsilon)$ and the $f(\varepsilon)$ values of the solvents are summarized in Table S4. In all cases, deviations of the experimental data from an accurate linear dependence are observed due to complicated and special interactions among the chromophores and the solvent. Nevertheless, if a linear fitting is attempted, the slopes are nearly similar for all chromophores and the larger deviations from the linear fitting are seen for the solvents TOL and $\mathrm{CHCl}_{3}$.

\section{Fluorescence dynamics}

The fluorescence dynamics have been studied in the ns timescale in order to deduce the excited state lifetime and its dependence on solvent and branching. Figure 3 shows characteristic results for $\mathbf{2 a}, \mathbf{2 b}$ and $\mathbf{2 c}$ while the corresponding results for $\mathbf{1 a}, \mathbf{1 b}$ and $\mathbf{1 c}$ are shown in Figure S4. The dynamics have been fitted by single or multi-exponential functions (Table S5).
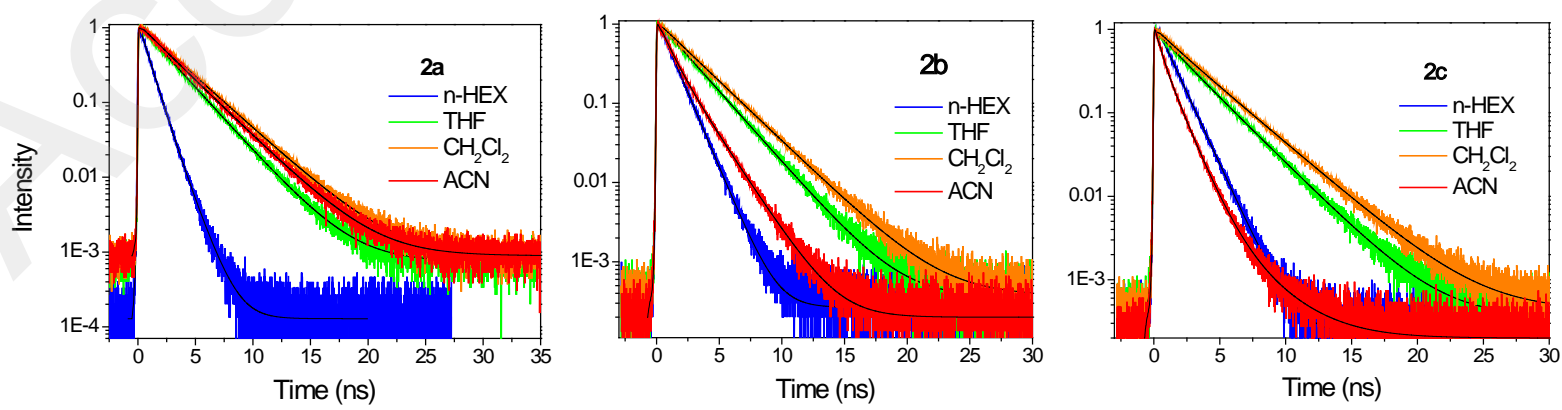

Figure 3. Nanosecond fluorescence dynamics of compounds $2 \mathbf{2 a}, \mathbf{2 b}$ and $\mathbf{2 c}$ in various solvents. 
The assignment of each lifetime component to a physical mechanism is not straightforward. Therefore, the average lifetime will be considered in this discussion. A first conclusion, that can be drawn, is that the diphenylamino compounds exhibit longer dynamics with larger average lifetimes compared to the dimethylamino ones, which can be associated to their higher fluorescence quantum yields. Besides, the average lifetimes of $1 \mathbf{a}$ and $\mathbf{2 a}$ increase with the solvent polarity, pointing to a stabilization of the excited state, while a slight decrease is exhibited in ACN only for $\mathbf{2 a}$. In $\mathbf{1 b}$ and $\mathbf{2} \mathbf{b}$, the average lifetimes again increase as the solvent polarity increases but in ACN, a clear and significant decrease is observed. This decrease of the average lifetime in ACN is even more dramatic in the case of octupolar compounds 1c and 2c. Similar behavior has been observed in the past for other compounds, in which the lifetimes decrease by more than one order of magnitude as the polarity increases, which was ascribed to the population of a dark ICT state with increased non-radiative decay rate as predicted by the energy gap law. ${ }^{28 c, 29 a, 30}$

The dynamics in the fs-ps timescale were studied for the compounds in series $\mathbf{2}$ for different emission wavelengths in two solvents, the apolar TOL and polar ACT, in order to examine fast spectral changes taking place before emission. Figure 4 presents representative dynamics for $\mathbf{2 b}$. The corresponding data for $\mathbf{2 a}$ and $\mathbf{2 c}$ are shown in Figures S5 and S6 respectively. In all cases, fast decays at short wavelengths and slow rises at long ones are observed pointing to a transient spectral shift towards low energies, which is more obvious in ACT due to its polar nature. The dynamics have been fitted by means of a global method. ${ }^{31}$ The results indicate that the spectral shift is due to the existence of two mechanisms taking place on $\sim 1$ ps and 110 ps for TOL while the corresponding times are smaller in ACT (Tables S6-S11). Both mechanisms have positive amplitude at short wavelengths which become negative at long ones pointing to the above mentioned spectral shift. 

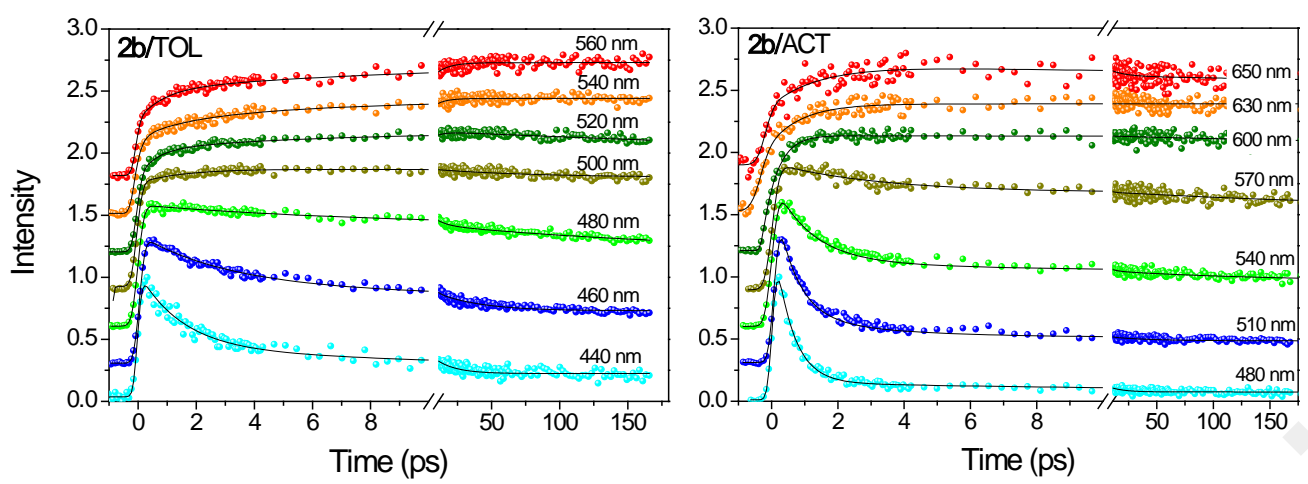

Figure 4. Femtosecond time resolved upconversion dynamics of $\mathbf{2 b}$ in TOL and ACT. The transients have been shifted for clarity.

The observed behavior i.e. the transient relaxation of the spectra towards lower energies, can be due to an energy transfer from the locally excited (LE) to the ICT state, to a solvent relaxation and to a structural reorganization of the excited state. ${ }^{32}$ In order to obtain a more specific understanding of the excited state photophysics, the time resolved emission spectra (TRES) were reconstructed and are shown in Figure 5. In general, the spectra do not largely differ upon branching but show striking differences upon increasing the polarity from TOL to ACT. In TOL, the transient red-shift is small and slow, while in ACT, a rapid and significant red-shift is observed in all molecules which mainly takes place on a $<1$ ps timescale indicating more important relaxation phenomena than in TOL. 

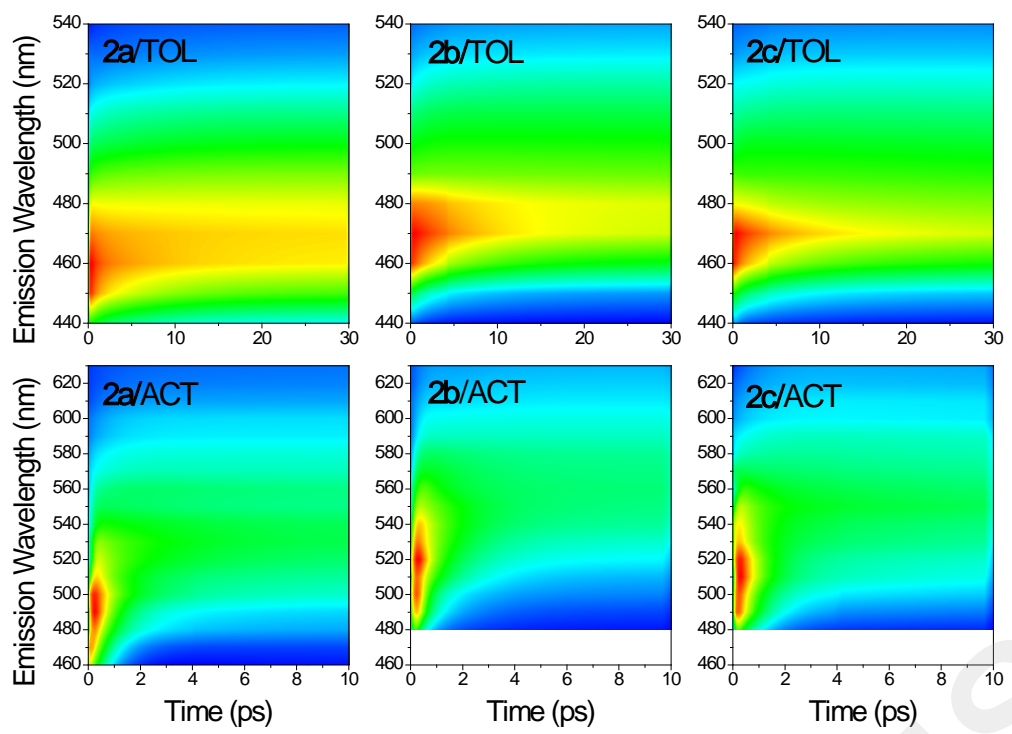

Figure 5. 2D plots of the TRES for compounds $\mathbf{2 a}, \mathbf{2} \mathbf{b}$ and $\mathbf{2} \mathbf{c}$ in TOL and ACT.

The TRES were fitted by a log-normal function (Figure S7 presents the spectra together with their fittings) in order to be able to measure the temporal shift of the spectral peak. Next, the solvent response function $C(t)=\frac{v(t)-v(\infty)}{v(0)-v(\infty)}$ (where $v(t), v(0)$ and $v(\infty)$ correspond to the peak frequency of the emission spectrum at time $t$, at zero time and at long times after the chromophore-environment system has been completely relaxed respectively) was calculated and plotted in Figure 6. Obviously, in TOL, $C(t)$ decays more slowly than in ACT pointing to a less intense and slower spectral relaxation. Fitting of $C(t)$ was made by means of a biexponential function and the results are shown in Table 2 together with the average time. A bi-exponential nature of the spectral shift function has been also reported in the past and points to a different effect of the adjacent solvent molecules to the solute compared to those that are further away. ${ }^{33}$ The lifetime components found for the solvent response function are longer than those reported by Maroncelli et al. having Coumarin 153 as a molecular probe (C153, its chemical structure is shown in Figure S6) ${ }^{34}$ indicating that the transient spectral shift originates by slower solvation as well as by slower conformational changes of the 
excited state that accompany ICT. Such a solute dependent relaxation dynamics has been also reported in the past addressing the effect of solute rotation on relaxation. ${ }^{35}$ Another indication that solvation is not the only mechanism leading to the transient spectral relaxation, comes from the observation of the change of the spectral shape with time and especially by their broadening (Figure S7), indicating that there is not a single emitting state that is gradually relaxed but a more complicated behavior is present involving more than one emitting state. ${ }^{36}$

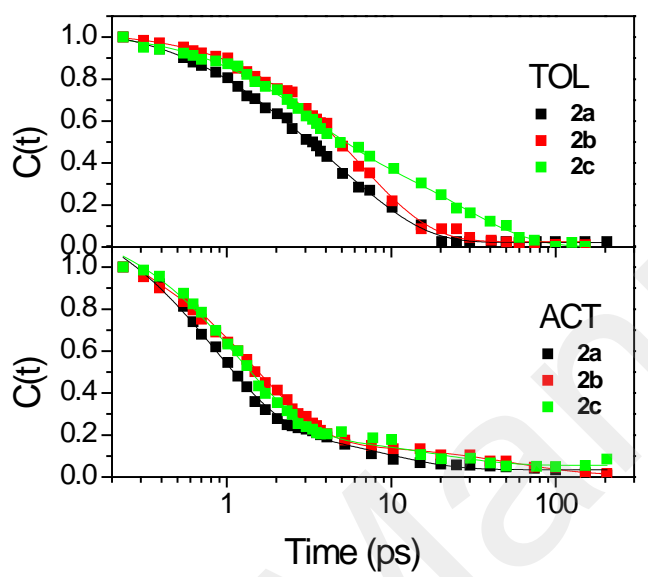

Figure 6. Time dependence of the solvent response function $C(t)$ of $\mathbf{2 a}, \mathbf{2} \mathbf{b}$ and $\mathbf{2} \mathbf{c}$ in TOL and ACT.

Table 2. Fitting parameters for the solvent response function, $C(t)$, for $\mathbf{2 a} \mathbf{a}, \mathbf{2 b}$ and $\mathbf{2 c}$ in TOL and ACT.

\begin{tabular}{ccccccc} 
Sample & Solvent & $\mathrm{A}_{1}$ & $\tau_{1}(\mathrm{ps})$ & $\mathrm{A}_{2}$ & $\tau_{2}(\mathrm{ps})$ & $\langle\tau\rangle(\mathrm{ps})$ \\
2a & $\mathrm{TOL}$ & 0.28 & 1.0 & 0.72 & 6.3 & 4.8 \\
2b & & 0.76 & 2.4 & 0.24 & 17 & 5.9 \\
2c & & 0.49 & 2.1 & 0.51 & 27 & 15 \\
2a & $\mathrm{ACT}$ & 0.98 & 0.7 & 0.02 & 7.4 & 0.83 \\
2b & & 0.90 & 1.0 & 0.10 & 57 & 3.6 \\
2c & & 0.87 & 1.0 & 0.13 & 15 & 2.8 \\
\hline
\end{tabular}

\section{Anisotropy dynamics}

Anisotropy dynamics are a valuable tool to determine the nature of the emitting state as well as the interactions among the branches and/or rotational movement. The initial anisotropy, $\mathrm{r}_{0}$, is a measure of the angle between absorption and emission dipoles and is expected to be 0.4 for linear molecules and 0.1 for octupolar ones, in the case where the energy is equally 
distributed among the branches. The latter is understood by the fact that the two lower lying one-photon allowed states in octupolar molecules, populated after state splitting, have perpendicularly polarized transition dipole moments. ${ }^{28 c}$ Therefore, the final anisotropy is calculated by $r=\sum_{i=1,2} f_{i} r_{\mathrm{i}}$ where $f_{i}$ are the fractional contribution of each one of these two states to absorption and $r_{i}$ their individual anisotropies which are either 0.4 or -0.2 respectively. When these two states have equal fractional contribution to absorption (i.e. $f_{1}=$ $f_{2}=0.5$ ) the final anisotropy of 0.1 is found.

The interactions among the branches such as coherent or incoherent energy transfer, are revealed by rapid drops of anisotropy taking place on the few tens of fs or few ps respectively. The anisotropy dynamics detected in the fs-ps timescale are shown in Figure 7 for 2a-2c. For 2a, the anisotropy decay is typical for linear molecules in dilute solutions. Specifically, 2a in TOL exhibits an $r_{0}$ of 0.36 and a single exponential decay of 85 ps due to rotational diffusion (Table 3). In ACT, $r_{0}$ is close to 0.4 as expected for linear molecules, and the anisotropy decay takes place on 50 ps. The anisotropy of $\mathbf{2 b}$ in both solvents is more complicated and exhibits a fast decay component of the order of 1-10 ps that can be due to interactions or energy spreading between the two branches (Table 3). On the other hand, $\mathrm{r}_{0}$ is smaller in ACT than in TOL (0.28 vs. 0.35), meaning that the orientation of the emission dipole of $\mathbf{2} \mathbf{b}$ is different in these two solvents, which leads us to the conclusion that the excited state is of different nature. It is plausible therefore, to conclude that in ACT, the emission is due to the ICT state, having a smaller $\mathrm{r}_{0}$ than the LE state.

Finally, 2c in both TOL and ACT exhibits a small $r_{0}$ value of 0.15 , followed by a slow rotational decay (>100 ps). The reduced $r_{0}$ value compared to $2 \mathbf{a}$ and $\mathbf{2 b}$ points that at $\mathbf{t}=0$, energy is distributed among the branches. However, the dynamics of this distribution is not observed (since no anisotropy decay is seen) and therefore it is considered to take place on an ultrafast timescale, i.e. faster than our IRF. In the past, anisotropy decays of $\sim 10$ fs have been 
reported for octupolar molecules, but of the reverse topology compared to the ones studied here i.e. $\mathrm{D}-(\pi-\mathrm{A})_{3}$, and have been attributed to coherent energy transfer. ${ }^{37}$ Although, an $\mathrm{r}_{0}$ value of 0.15 reveals energy distribution, it is however, higher than 0.1 which is expected in the case of an homogeneously distribution of energy among branches, according to the law of adding anisotropies. ${ }^{38}$ Upon examining the anisotropy of 2c in the 1-10 ps timescale, no further decrease is observed meaning that incoherent energy hopping is not operative. This in agreement with a previous work of some of us, where compounds with olefinic bridges between the donor and acceptor groups, did not exhibit incoherent energy transfer while those with acetylenic bridge showed a few ps depolarization due to energy hopping. ${ }^{15 c}$ Overall, based on the anisotropy data on the octupolar-like chromophore $\mathbf{2 c}$, which however do not have the C3 symmetry, it is concluded that energy is distributed coherently among branches on an ultrafast timescale dramatically reducing the $\mathrm{r}_{0}$ compared to $\mathbf{2} \mathbf{a}$ and $\mathbf{2} \mathbf{b}$. Next, energy is localized on the branches and no energy hopping takes place.

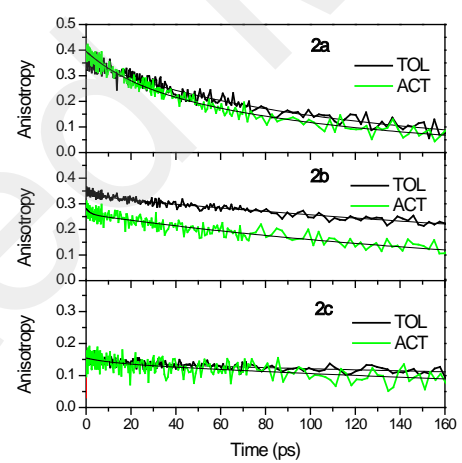

Figure 7. Femtosecond time resolved anisotropy dynamics for $\mathbf{2 a}, \mathbf{2} \mathbf{b}$ and $\mathbf{2 c}$ in TOL and ACT (exc. $400 \mathrm{~nm}$ ). Detection is made at the peaks of the fluorescence spectra

\begin{tabular}{ccccccc} 
Sample & Solvent & $\mathrm{r}_{0}$ & $\mathrm{~A}_{1}$ & $\tau_{1}(\mathrm{ps})$ & $\mathrm{A}_{2}$ & $\tau_{2}(\mathrm{ps})$ \\
$\mathbf{2 a}$ & $\mathrm{TOL}$ & 0.36 & & & 0.36 & 85 \\
$\mathbf{2 b}$ & & 0.35 & 0.02 & 6.5 & 0.33 & $>100$ \\
$\mathbf{2 c}$ & & 0.16 & & & 0.14 & $>100$ \\
$\mathbf{2 a}$ & $\mathrm{ACT}$ & 0.40 & & & 0.40 & 50 \\
$\mathbf{2 b}$ & & 0.28 & 0.03 & 1.9 & 0.25 & $>100$ \\
$\mathbf{2 c}$ & & 0.15 & & & 0.15 & $>100$ \\
\hline
\end{tabular}

Table 3. Fitting parameters for the anisotropy dynamics for $\mathbf{2 a}, \mathbf{2 b}$ and $\mathbf{2 c}$ in TOL and ACT (exc. $400 \mathrm{~nm}$ ). 


\section{Two-photon absorption}

Figure 8 displays the 2PA spectra for all the compounds in the 700-1000 nm range in DCM. The normalized 1PA spectra have been also superimposed to have a straightforward comparison with their respective 2PA spectra. Table 4 gathers the related 2PA data.

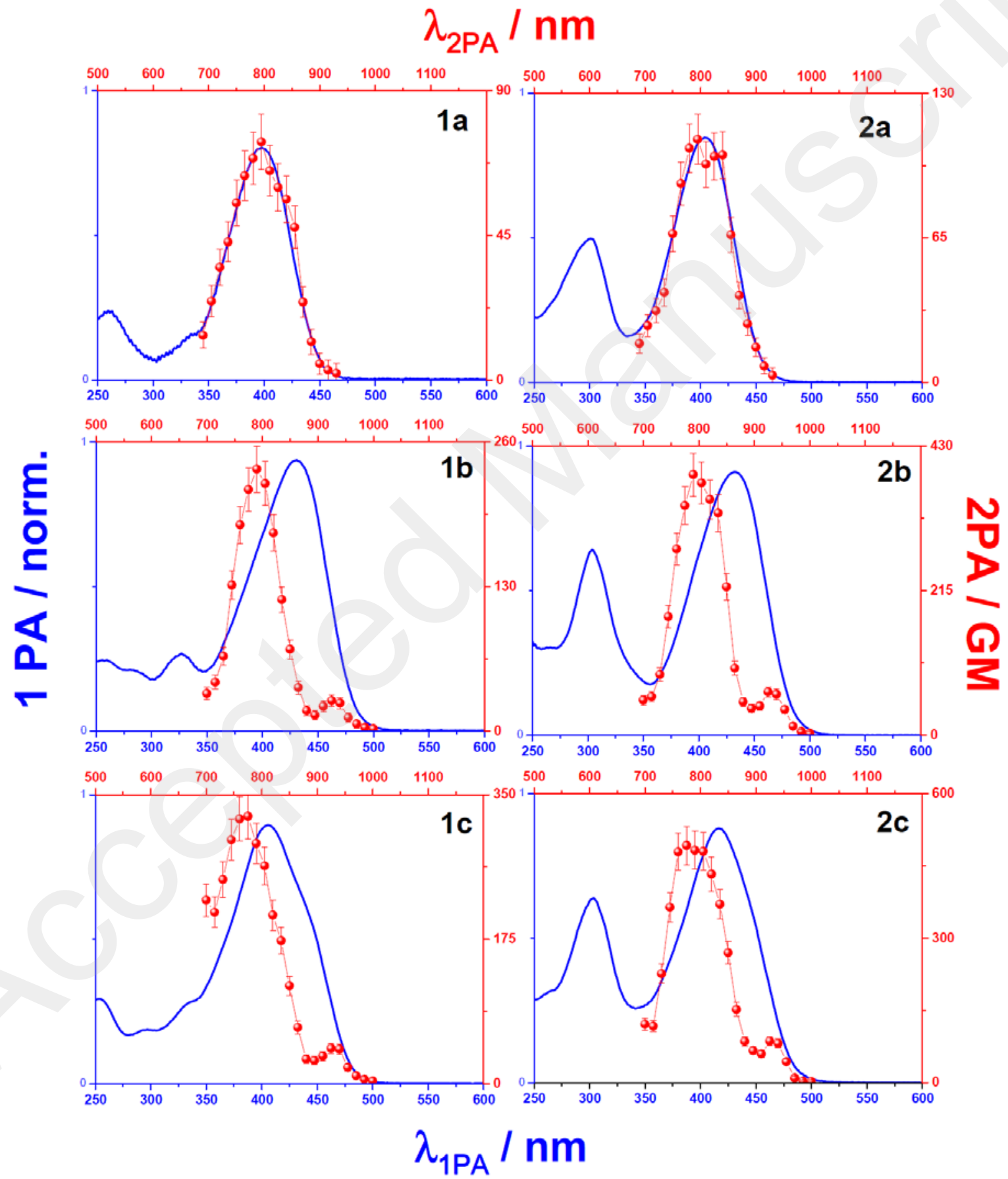


Figure 8. One- (full lines) and two-photon (dots) absorption spectra for compounds in DCM. The 2PA spectra are presented as function of the excitation laser wavelength (upper horizontal scale). The normalized 1PA spectra are shown at the 1PA wavelength (lower horizontal scale)

Within our spectral resolution, the 2PA bands of the dipolar chromophores 1a and 2a match relatively well the 1PA ones. This confirms that the first excitation (also referred to as the $\mathrm{S}_{0}$ $\mathrm{S}_{1}$ transition) is both one- and two-photon active for both compounds. Whereas the small redshift observed in the 1PA spectra (Table 1) in moving from 1a to 2a is hardly visible in the 2PA spectra, substitution of the dimethylamino group by the diphenylamino ones leads to noticeable increase of the 2PA cross section as expected and qualitatively reproduced by TDB3LYP calculations (Figure S9) as well as using a simple two-state model (Table S12).

By contrast, the main 2PA band of the V-shaped quadrupolar chromophores $\mathbf{1 b}$ and $\mathbf{2 b}$ does not coincide with the 1PA band and is positioned in the higher energy region $\left(\lambda_{2 P A}^{\max } \sim\right.$ $800 \mathrm{~nm}$ ). According to the dipole selection rule for centrosymmetric systems, such a 2PA band should be reasonably assigned to the second excitation transition $\left(\mathrm{S}_{0}-\mathrm{S}_{2}\right.$, see Figure $\mathrm{S} 10$ for a theoretical characterization) of each chromophore. In this case, it should be noted that the lowest energy excitation is theoretically two-photon forbidden but is, in the present case, partially allowed as a result of lower symmetry. This latter effect is indeed observed since the 2PA spectra of 1b-c and 2b-c exhibit a weakly intensive band centered at $\sim 920 \mathrm{~nm}$. For this lowestenergy 2PA resonance, the evolution of the corresponding $\delta^{\mathrm{MAX}}$ is very interesting since it can be reasonably rationalized on the basis of the simple two-state model. ${ }^{39}$ In this approach, $\delta^{\mathrm{MAX}}$ can be approximated by the following relation:

$$
\delta^{M A X} \propto \frac{\mu_{a b s}^{2} \cdot \Delta \mu_{01}^{2}}{\Gamma_{01}}
$$

Where $\Gamma_{01}$ corresponds to the damping factor relative to the $S_{0}-S_{1}$ transition. Since all multibranched dyes display a 1PA lowest-energy band with a comparable half width at halfmaximum, this damping factor should be maintained equivalent for all derivatives. $\mu_{a b s}$ 
corresponds to the lowest-energy transition dipole moment. It should be noted that the values calculated for $\mu_{a b s}$ (see Table 1) are presumably overestimated in our case since the integration over the longest wavelength 1PA band encompasses contributions of other $S_{0}-S_{n}$ transitions. Finally, the permanent dipole moment change between ground and excited states $\left(\Delta \mu_{01}\right)$ can be estimated for $\mathbf{1 b}-\mathbf{c}$ and $\mathbf{2 b}-\mathbf{c}$ according to the solvation effects on their respective Stokes shifts $\left(v^{S T}=v_{a b s}-v_{e m}\right.$ in $\left.\mathrm{cm}^{-1}\right)$. According to the theory of dielectric polarization, ${ }^{40} \Delta \mu_{g e}$ can be approximated as follows:

$$
\Delta \mu_{01}^{2} \propto \frac{\partial v^{S T}}{\partial F} \cdot a^{3}
$$

Where $\mathrm{F}(\varepsilon, n)=(\varepsilon-1) /(2 \varepsilon+1)-\left(n^{2}-1\right) /\left(2 n^{2}+1\right)$ is the solvent polarity parameter with $\varepsilon$ the dielectric constant (as defined before) and $n$ the refractive index of the solvent. The Onsager radius $a$ defined as the solvent shell around the chromophore was approximated, following Lippert's suggestion ${ }^{41}$ for non-spherical chromophores, as $40 \%$ of the longest axis of each linear stilbenoid synthon ${ }^{42}$ (i.e. 1a and 2a). According DFT fully optimized geometries of the dipolar derivatives, the estimated values of $a$ are ca. $5.2 \AA$ for the Nmethylated compounds and $5.8 \AA$ for the N-phenylated ones. From the plot of $\frac{\delta^{\max }}{\mu_{a b s}^{2}} v s$. $\frac{\partial v^{S T}}{\partial F} \cdot a^{3}$ a good linear correlation $\left(\mathrm{R}^{2}=0.98\right)$ is obtained for our multibranched series (Figure 9). Therefore, this agreement suggests that the two-state model reasonably accounts for the evolution of the maximum 2PA cross section of the lowest-energy resonance within this multibranched series. This has been further checked using computed dipole moments of 2a-b (Table S12). 


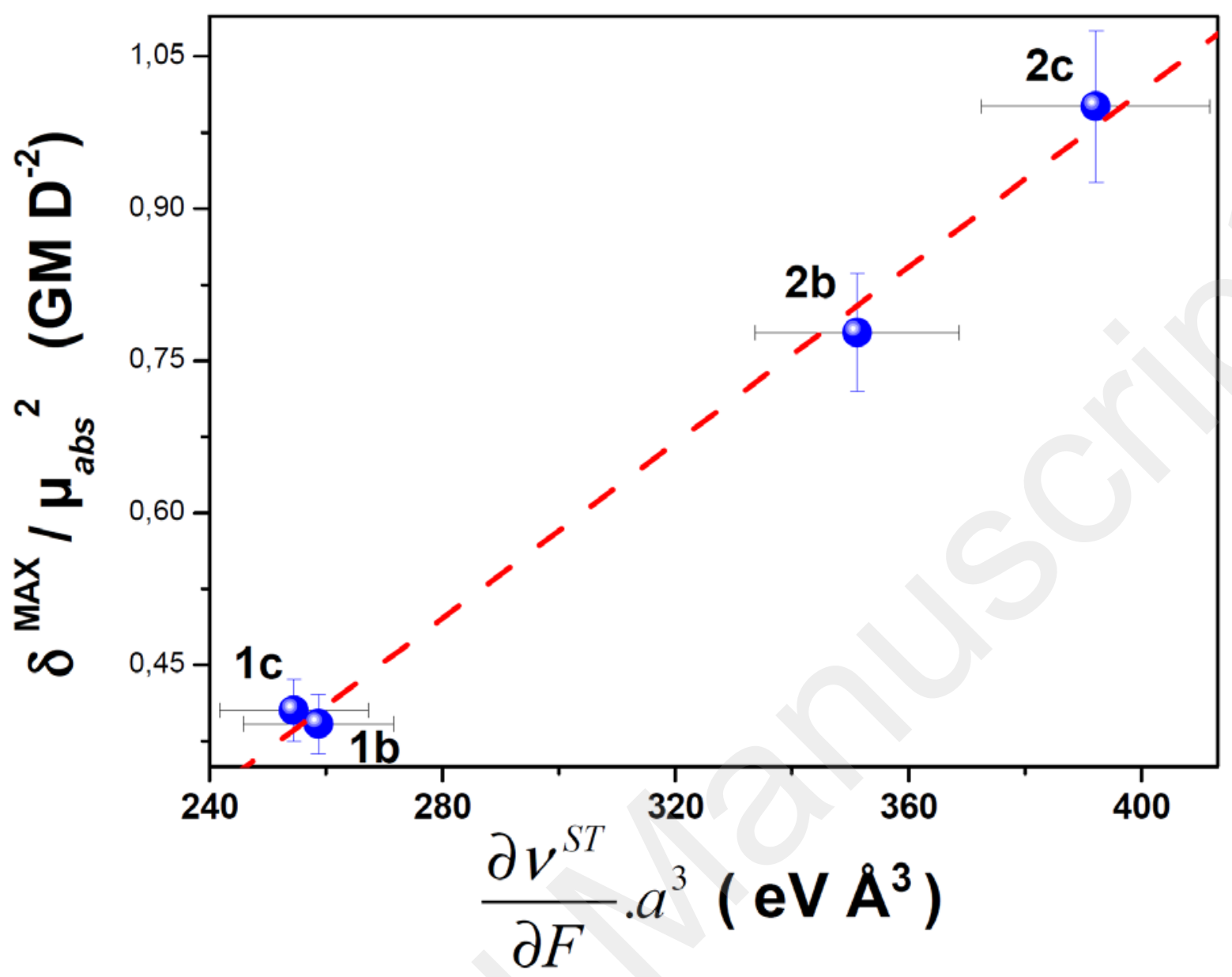

Figure 9. Correlation between $\frac{\delta^{\max }}{\mu_{a b s}^{2}}$ and $\frac{\partial v^{S T}}{\partial F} \cdot a^{3}$ parameters (see equation 1 and 2 in the text and table S14)

Now, considering the whole investigated spectral region, overall, the 2PA responses of the branched compounds are significantly enhanced with respect to the dipolar chromophores, with noticeable blue-shift of their maxima compared to the 1PA, as a result of a main contribution stemming from the second $\mathrm{S}_{0}-\mathrm{S}_{2}$ transition.

Interestingly, the introduction of a 4-aminostyryl branch into the $\mathrm{C} 2$ position of the pyrimidine core does not dramatically affect the shape of the 2PA spectra with respect to those of their respective V-shaped quadrupoles, when compared to others series with increasing number of branches. ${ }^{15 f, g}$ Such a specific band shape is related to the lack of 3-fold symmetry already discussed while considering linear absorption. Whereas the two lowest 
excited states are responsible for the 1PA band, they retain sizeable 2PA activity. On the other hand, the third excited state, which has significantly smaller oscillator strength for 1PA, but still sizeable (Table S3), has the largest 2PA activity and is responsible for the blue shifted 2PA maxima with respect to their dipolar and V-shaped analogues.

As shown in Table 4, going from methyl to phenyl $N, N$ '-substitution induces a substantial increase of the maximum two-photon absorption cross-section $\left(\delta_{\mathrm{MAX}}\right)$. If we also take into account the higher fluorescence quantum yields of the phenyl substituted compounds, then these compounds are considered better candidates for 2PA fluorescence applications. The maximum 2PA cross-sections of dipolar systems are moderate with values in the 80-120 GM range, whereas multibranched chromophores present significantly higher $\delta_{\text {MAX }}$ ranging from 200 to 500 GM. Overall, the enhancement and spectral shift remain moderated due to the spread of 1PA and 2PA activity over several excited states, as a result of lack of symmetry. In order to further compare the intrinsic $2 \mathrm{PA}$ properties within the series, the maximum 2PA cross-section ( $\left.\delta_{\text {MAX }}\right)$ of each chromophore has been normalized by the square of the effective number of electrons $\left(\mathrm{N}_{\text {eff }}\right)$ which contribute to the nonlinear response of the molecule. According to the definition proposed by Kuzyk et al., ${ }^{43}$ the values of $\mathrm{N}_{\text {eff }}$ and $\delta_{\mathrm{MAX}} / \mathrm{N}^{2}$ eff have been reported in Table 4. As previously indicated, for a given number of branches, the $\mathrm{N}$ phenylation clearly improves the intrinsic 2PA properties more significantly than $\mathrm{N}$ methylation. It can also be inferred from this normalization methodology that the branching effect of the 4-aminostyryl on the pyrimidine C2 position has a significant detrimental impact on the intrinsic 2PA properties, as compared to related chromophores bearing 3-fold symmetry. Meanwhile, the present synthetic strategy affords branched chromophores having improved 2PA responses in the same spectral region as their dipolar counterparts with additional broadening particularly on the blue-side of the spectra.

\begin{tabular}{ccccc} 
Sample & $\lambda_{\text {MAX }}(\mathrm{nm})$ & $\delta_{\mathrm{MAX}}{ }^{a}(\mathrm{GM})$ & $\mathrm{N}_{\text {eff }}$ & $\delta_{\mathrm{MAX}} / \mathrm{N}_{\text {eff }}{ }^{2}$ \\
$\mathbf{1 a}$ & 795 & 73 & 14 & 0.37 \\
\hline
\end{tabular}




\begin{tabular}{ccccc}
\hline $\mathbf{1 b}$ & 790 & 235 & 22 & 0.49 \\
$\mathbf{1 c}$ & 775 & 324 & 30 & 0.36 \\
2a & 795 & 109 & 16 & 0.41 \\
2b & 790 & 387 & 25 & 0.61 \\
2c & 775 & 492 & 33 & 0.44 \\
\hline
\end{tabular}

${ }^{a}$ Experimental error $15 \%$

Table 4. Experimental two-photon absorption properties of chromophores 1a-c and 2a-c in $\mathrm{CH}_{2} \mathrm{Cl}_{2}$. $\delta_{\text {MAX }}$ is the 2PA cross-section and $\mathrm{N}_{\text {eff }}$ the effective number of electrons according to the counting methodology proposed by Kuzyk et al. ${ }^{43}$.

\section{Conclusions}

The linear and non-linear optical properties of a series of styrylpyrimidines have been studied addressing the effect of solvent, electron donating group and branching. The styrylpyrimidines bear dimethylamino or diphenylamino donors while the properties of the molecules with A-( $\pi-\mathrm{D})_{3}$ structure have been compared to those of dipolar and quadrupolar counterparts. Steady state spectroscopy, fs to ns time resolved spectroscopy and a 2PA induced fluorescence technique have been used in this study and comforted by quantum chemical calculations. The pyrimidine core has not a C3 symmetry, unlike triphenylbenzene or triphenylamine and this changes significantly the branching effects in terms of spectral shift and amplitude as well as excited state dynamics. The 2PA measurements showed that the 2PA cross sections increase by changing the electron donating groups from dimethylamino to diphenylamino and by increasing the branching number. Specifically, 2PA cross section values as high as $500 \mathrm{GM}$ have been observed for the pseudo-octupolar diphenylamino A- $(\pi$ D) ${ }_{3}$ molecule in dichloromethane. The shape of the 2PA spectrum of the three-branched chromophores $\mathbf{1 c}$ and $\mathbf{2 c}$ is similar to that of the two-branched ones, clearly exhibiting that the incorporation of the third branch does not significantly affect the molecular symmetry. We have therefore developed a strategy that enhances the TPA response while maintaining the spectral position.

\section{Acknowledgements}


C. K. acknowledges support by the Grand Equipement National de Calcul Intensif (GENCI) through HPC resources of CINES and IDRIS (grant 2019-A0060800649). M. F. acknowledges the Région Bretagne for her Ph. D. Funding.

${ }^{1}$ (a) S. Achelle, J. Rodríguez-López, and F. Robin-le Guen, ChemistrySelect 2018, 3, 1852 1885; (b) G. N. Lipunova, E. V. Nosova, V. N. Charushin and O. N. Chupakhin, Curr. Org. Synth. 2018, 15, 793-814; (c) S. Achelle and N. Plé, Curr. Org. Synth. 2013, 9, 163-187.

${ }^{2}$ see for example: (a) J. Rodriguez-Aguilar, M. Vidal, C. Pastenes, C. Aliaga, M. C. Rezende, and M. Dominguez, Photochem. Photobiol. 2018, 94, 1100-1108; (b) E. V. Verbitskiy E. M. Dinastiya A. A. Baranova, K. O. Khokhlov, R. D. Chuvashov, Y. A. Yakovleva, N. I. Makarova, E. V. Vetrova, A. V. Metelitsa, P. A. Slepukhin, G. L. Rusinov, O. N. Chupakhin and V. N. Charushin, Dyes Pigm. 2018, 159, 35-44; (c) R. Komatsu, T. Ohsawa, H. Sasabe, K. Nakao, Y. Hayasaka and J. Kido, ACS Appl. Mater. Interfaces 2017, 9, 4742-4749; (d) A. S. Cornec C. Baudequin, C. Fiol-Petit, N. Plé, G. Dupas and Y. Ramondenc, Eur. J. Org. Chem. 2013, 1908-1915; (e) T. Serevicius, T. Buciunas, J. Bucevicius, J. Dodonova, S. Tumkevicius, K. Kazlauskas and S. Jursenas, J. Mater. Chem. C 2018, 6, 11128-11136.

${ }^{3}$ L. Pascal, J. J. Vanden Eynde, Y. Van Haverbeke, P. Dubois, A. Michel, U. Rant, E. Zojer, G. Jeising, L. O. Van Dorn, N. E. Gruhn, J. Cornil and J. L. Brédas, J. Phys. Chem. B 2002, 106, 6442-6450.

${ }^{4}$ (a) S. Achelle, I. Nouira, B. Pfaffinger, Y. Ramondenc, N. Plé and J. Rodríguez-López, J. Org. Chem. 2009, 74, 3711-3717; (b) S. Achelle, A. Barsella, C. Baudequin, B. Caro and F. Robin-le Guen J. Org. Chem. 2012, 77, 4087-4096; (c) S. Achelle and F. Robin-le Guen Tetrahedron Lett. 2013, 54, 4491-4496; (d) S. Achelle, L. Bodiou, J. Charrier and F. Robin-le Guen, F. C. R. Chimie 2016, 19, 279-285; (e) C. Hadad, S. Achelle, J. C. García-Martínez and J. Rodríguez-López, J. Org. Chem. 2011, 76, 3837-3845; (f) H. Akdas-Kilig, M. Godfroy, J.- 
L. Fillaut, B. Donnio, B. Heinrich, P. Kedziora, J.-P. Malval, A. Spangenberg, S. van Cleuvenbergen K. Claysand F. Camerel, J. Phys. Chem. C 2015, 119, 3697-3710; (g) A. Boländer, D. Kiesser, C. Voss, S. Bauer, C. Schön, S. Burgold, T. Bittner, J. Hölzer, R. Heyny-von Haußen, G. Mall, V. Goetschy, C. Czech, H. Knust, R. Berger, J. Herms, I. Hilger and B. Schmidt, J. Med. Chem. 2012, 55, 9170-9180; (h) S.-i. Kato, Y. Yamada, H. Hiyoshi, K. Umezu and Y. Nakamura, J. Org. Chem. 2015, 80, 9076-9090.

${ }^{5}$ X. Xiong, Q. Zhai, L. Xue, F. Zheng and X. Xie, Chin. J. Appl. Chem. 2012, 29, 1262-1265.

${ }^{6}$ (a) C. Hadad, S. Achelle, I. López-Solera, J. C. García-Martínez and J. Rodríguez-López, Dyes Pigm. 2013, 97, 230-237; (b) S. Achelle, J. Rodríguez-López, F. Bureš and F. Robin-le Guen, Dyes Pigm. 2015, 121, 305-311.

${ }^{7}$ M. Fecková, P. le Poul, F. Robin-le Guen, T. Roisnel, O. Pytela, M. Klikar; F. Bureš and S. Achelle, J. Org. Chem. 2018, 83, 11712-11726.

8 S. Achelle, J. Rodríguez-López, F. Bureš and F. Robin-le Guen, Chem. Rec. doi: 10.1002/tcr.201900064

${ }^{9}$ (a) S. Achelle, J. Rodríguez-López, C. Katan and F. Robin-le Guen, J. Phys. Chem. C 2016, 120, 26986-26995; (b) D. Liu, Z. Zhang, H. Zhang and Y. Wang, Chem. Commun. 2013, 49, 10001-10003; (c) S. Achelle, J. Rodríguez-López, M. Larbani, R. Plaza-Pedroche and F. Robin-le Guen, Molecules 2019, 24, 1742

${ }^{10}$ (a) S. van Cleuvenbergen, P. Kedziora, J. L. Fillaut, T. Verbiest, K. Clays, H. Akdas-Kilig and F. Camerel, Angew. Chem. Int. Ed. 2017, 56, 9546-9550; (b) R. J. Durand, S. Achelle, S. Gauthier, N. Cabon, M. Ducamp, S. Kahlal, J.-Y. Saillard, A. Barsella and F. Robin-le Guen, Dyes Pigm. 2018, 155, 68-74; (c) S. Achelle, S. Kahlal, A. Barsella, J.-Y. Saillard, X. Che, J. Vallet, F. Bureš, B. Caro, and F. Robin-le Guen, Dyes Pigm. 2015, 113, 562-570; (d) S. Achelle, J.-P. Malval, S. Aloise, A. Barsella, A. Spangenberg, L. Mager, H. Akdas-Kilig, J.-L. Fillaut, B. Caro and F. Robin-le Guen, ChemPhysChem 2013, 14, 2725-2736. 
${ }^{11}$ (a) P. Savel, H. Akdas-Kilig, J.-P. Malval, A. Spangenberg, T. Roisnel and J.-L. Fillaut, J. Mater. Chem. C 2014, 2, 295-305; (b) D. Cvejn, S. Achelle, O. Pytela, J.-P. Malval, A. Sangenberg, N. Cabon, F. Bureš and F. Robin-le Guen, Dyes Pigm. 2016, 124, 101-109; (c) B. Liu, X.-L. Hu, J. Liu, Y.-D. Zhao, Z.-L. Huang, Tetrahedron Lett. 2007, 48, 5958-5962; (d) A. Wang, L. Long, S. Meng, X. Li, W. Zhao, Y. Song, M. P. Cifuentes, M. G. Humphrey and C. Zhang, Org. Biomol. Chem. 2013, 23, 4250-4257.

12 (a) L. Li, J. Ge, H. Wu, Q.-H. Xu and S. Q. Yao, S. J. Am. Chem. Soc. 2012, 134, $12157-$ 12167; (b) Z. Na, L. Li, M. Uttamchandani and S. Yao, Chem. Commun. 2012, 48, 73047306; (c) Q. Zhang, X. Tian, Z. Hu, C. Brommesson, J. Wu, H. Zhou, J. Yang, Z. Sun, Y. Tian and K. Uvdal, Dyes Pigm. 2016, 126, 286-295; (d) B. Liu, H.-L. Zhang, J. Liu, Y.-D. Zhao, Q.-M. Luo and Z.-L. Huang, J. Mater. Chem. 2007, 17, 2921-2929; (e) Q. Zhang, L. Luo, H. Xu, Z. Hu, C. Brommesson, J. Wu, Z. Sun, Y. Tian and K. Uvdal, New J. Chem. 2016, 40, 3456-3463; (f) J. Yeng, W. Hu, H. Li, H. Hou, Y. Tu and B. Liu, Photochem. Photobiol Sci. 2018, 17, 474-481.

${ }^{13}$ L. Li, Y.-P. Tian, J.-X. Yang, P.-P. Sun, J.-Y. Wu, H.-P. Zhou, S.-Y. Zhang, B.-K. Jin, X.J. Xing, C.-K. Wang, M. Li, G.-H. Cheng, H.-H. Tang, W.-H. Huang, X.-T. Tao, M.-H. Jiang, Chem. Asian J. 2009, 4, 668-680.

14 J.-P. Malval, S. Achelle, L. Bodiou, A. Sangenberg, L. Chia Gomez, O. Soppera and F. Robin-le Guen, J. Mater. Chem. C 2014, 2, 7869-7880.

${ }^{15}$ (a) F. Terenziani, C. Le Droumaguet, C. Katan, O. Mongin and M. Blanchard-Desce, ChemPhysChem. 2007, 8, 723-734; (b) Y. Wang, T. Li, Y. Yin, Y. Jiang, G. Wang, D. Liu and J. Hua Optik, 2017, 142, 163-167; (c) K. Seintis, D. Agathangelou, D. Cvejn, N. Almonasy, F. Bureš, V. Giannetas and M. Fakis, Phys. Chem. Chem. Phys. 2017, 19, 1648516497; (d) R. D. Fonseca, M. G. Vivas, D. L. Silva, G. Eucat, Y. Bretonniere, C. Andraud, C. R. Mendonca, L. De Boni, J. Phys. Chem. Lett. 2019, 10, 2214-2219; (e) C. Katan, S. Tretiak, 
M. H. V. Werts, A. J. Bain, R. J. Marsh, N. Leonczek, N. Nicolaou, E. Badaeva, O. Mongin and M. Blanchard-Desce, J. Phys. Chem. B 2007, 111, 9468-9483; (f) D. Cvejn, E. Michail, K. Seintis, M. Klikar, O. Pytela, T. Mikysek, N. Almonasy, M. Ludwig, V. Giannetas, M. Fakis and F. Bureš, RSC Adv. 2016, 6, 12819-12828; (g) C. Katan, F. Terenziani, O. Morgin, M. H. V. Werts, L.Porrès, T. Pons, J. Mertz, S. Tretiak and M. Blanchard-Desce, J. Phys. Chem. A, 2005, 109, 3024-3037.

${ }^{16}$ (a) L. Zou, Z. Liu, X. Yan, Y. Liu, Y. Fu, J. Liu, Z. Huang, X. Chen and J. Qin, Eur. J. Org. Chem. 2009, 5587-5593; (b) Y. M. Porotnik, V. Hugues, M. Blanchard-Desce and D. T. Gryko, Chem. Eur. J. 2012, 18, 9258-9266; (c) G. Argouarch, R. Veillard, T. Roisnel, A. Amar, H. Meghezzi, A. Boucekkine, V. Hugues, O. Mongin, M. Blanchard-Desce and F. Paul, Chem. Eur. J. 2012, 18, 11811-11827.

${ }^{17}$ (a) F. Kournoutas, K. Seintis, N. Karakostas, J. Tydlitát, S. Achelle, G. Pistolis, F. Bureš and M. Fakis, J. Phys. Chem. A 2019, 123, 417-428; (b) N. Karakostas, E. Martinou, A. Kaloudi-Chantzea, K. Seintis, H. Oberacher, F. Pitterl, M. Fakis, J. K. Kallitsis and G. Pistolis, Faraday Disc., 2015, 185, 433-454.

${ }^{18}$ N. Droseros, K. Seintis, M. Fakis, S. Gardelis and A. Nassiopoulou, J. Lumin., 2015, 167, 333-338.

${ }^{19}$ C. Xu, W. W. Webb, J. Opt. Soc. Am. B 1996, 13, 481-491.

${ }^{20}$ M. A. Albota, C. Xu and W. W. Webb, Appl. Opt. 1998, 37, 7352-7356.

${ }^{21}$ Gaussian 16, Revision B.01, M. J. Frisch, G. W. Trucks, H. B. Schlegel, G. E. Scuseria, M. A. Robb, J. R. Cheeseman, G. Scalmani, V. Barone, G. A. Petersson, H. Nakatsuji, X. Li, M. Caricato, A. V. Marenich, J. Bloino, B. G. Janesko, R. Gomperts, B. Mennucci, H. P. Hratchian, J. V. Ortiz, A. F. Izmaylov, J. L. Sonnenberg, D. Williams-Young, F. Ding, F. Lipparini, F. Egidi, J. Goings, B. Peng, A. Petrone, T. Henderson, D. Ranasinghe, V. G. Zakrzewski, J. Gao, N. Rega, G. Zheng, W. Liang, M. Hada, M. Ehara, K. Toyota, R. Fukuda, 
J. Hasegawa, M. Ishida, T. Nakajima, Y. Honda, O. Kitao, H. Nakai, T. Vreven, K. Throssell, J. A. Montgomery, Jr., J. E. Peralta, F. Ogliaro, M. J. Bearpark, J. J. Heyd, E. N. Brothers, K. N. Kudin, V. N. Staroverov, T. A. Keith, R. Kobayashi, J. Normand, K. Raghavachari, A. P. Rendell, J. C. Burant, S. S. Iyengar, J. Tomasi, M. Cossi, J. M. Millam, M. Klene, C. Adamo, R. Cammi, J. W. Ochterski, R. L. Martin, K. Morokuma, O. Farkas, J. B. Foresman, and D. J. Fox, Gaussian, Inc., Wallingford CT, 2016.

${ }^{22}$ C. Adamo and V. Barone, J. Chem. Phys., 1999, 110, 6158-6169.

${ }^{23}$ T. Yanai, D. Tew and N. Handy, Chem. Phys. Lett., 2004, 393, 51-57.

${ }^{24}$ S. Tretiak and V. Chernyak, J. Chem. Phys. 2003, 119, 8809

${ }^{25}$ F. Terenziani, C. Katan, E. Badaeva, S. Tretiak and M. Blanchard-Desce, Adv. Mater., 2008, 20, 4641-4678.

${ }^{26}$ F. Terenziani, A. Painelli, C. Katan, M. Charlot and M. Blanchard-Desce J. Am. Chem. Soc. 2006, 128, 15742-15755.

${ }^{27}$ F. Terenziani, C. Sissa and A. Painelli, J. Phys. Chem. B 2008, 112, 5079-5087.

${ }^{28}$ (a) C. Katan, F. Terenziani, C. Le Droumaguet, O. Mongin M. H. V. Werts, S. Tretiak and M. Blanchard-Desce, SPIE 2005, 5935, 593503; (b) L. Yan, X. Chen, Q. He, Y. Wang, X. Wang, Q. Guo, F. Bai and A. Xia, J. Phys. Chem. A, 2012, 116, 8693-8705; (c) Y. Li, M. Zhou, Y. Niu, Q. Guo and A. Xia, J. Chem. Phys., 2015, 143, 034309-1-034309-12.

${ }^{29}$ (a) J. Jiang, A. Alsam, S. Wang, S. M. Aly, Z. Pan, O. F. Mohammed and K. S. Schanze, J. Phys. Chem. A, 2017, 121, 4891-4901; (b) C. Sissa, V. Parthasarathy, D. Drouin-Kucma, M. H. V. Werts, M. Blanchard-Desce and F.Terenziani, Phys. Chem. Chem. Phys., 2010, 12, 11715-11727.

${ }^{30}$ E. Ishow, G. Clavier, F. Miomandre, M. Rebarz, G. Buntinx and O. Poizat, Phys. Chem. Chem. Phys., 2013, 15, 13922-13939. 
${ }^{31}$ N. Banerji, S. Cowan, E. Vauthey, and A. J. Heeger J. Phys. Chem. C 2011, 115, 97269739.

${ }^{32}$ P. K. Singh, S. Nath, M. Kumbhakar, A. C. Bhasikuttan and H. Pal, J. Phys. Chem. A 2008, 112, 5598-5603.

33 (a) M. Maroncelli, J. Mol. Liq. 1993, 57, 1-37. (b) W. Jarzeba, G. C. Walker, A. E. Johnson and P. F. Barbara, Chem. Phys. 1991, 152, 57-68; (c) M. A. Kahlow, T. J. Kangand P. F. Barbara, J. Chem. Phys. 1988, 88, 2372- 2378.

34 (a) M. L. Horng, J. A. Gardecki, A. Papazyan and M. Maroncelli, J. Phys. Chem., 1995, 99, 17311-17337; (b) L. Reynolds, J. A. Gardecki, S. J. V. Frankland, M. L. Horng and M. Maroncelli, J. Phys. Chem., 1996, 100, 10337-10354.

${ }^{35}$ M. Sajadi, M. Weinberger, H.-A. Wagenknecht and N. P. Ernsting, Phys. Chem. Chem. Phys. 2011, 13, 17768-17774.

${ }^{36}$ (a) L. A. Gearheart, M. M. Somoza, W. E. Rivers, C. J. Murphy, R. S. Coleman and M. A. Berg, J. Am. Chem. Soc. 2003, 125, 11812- 11813. (b) C. F. Chapman, R. S. Fee and M. Maroncelli, J. Phys. Chem. 1995, 99, 4811-4819.

${ }^{37}$ (a) O. Varnavski, T. Goodson III, L. Sukhomlinova and R.Twieg, J. Phys. Chem. B, 2004, 108, 10484-10492; (b) Y. Wang, M. I. Ranasinghe, T. Goodson III, J. Am. Chem. Soc., 2003, 125, 9562-9563; (c) O. P. Varnavski, J. C. Ostrowski, L. Sukhomlinova, R. J. Twieg, G. C. Bazan, T. Goodson III, J. Am. Chem. Soc., 2002, 124, 1736-1743.

${ }^{38}$ G. Weber, Biochem. J., 1952, 51, 145-155.

39 a) T. Kogej, D. Beljonne, F. Meyers, J. W. Perry, S. R. Marder and J. L. Brédas, Chem. Phys. Lett., 1998, 298, 1-6; b) A. Rebane, M. Drobizhev, N. S. Makarov, E. Beuerman, J. E. Haley, D. M. Krein, A. R. Burke, J. L. Flikkema and T. M. Cooper, J. Phys. Chem. A, 2011, 115, 4255-4262; c) M. G. Vivas, D. L. Silva, J. Malinge, M. Boujtita, R. Zalesny, W. 
Bartkowiak, H. Agren, S. Canuto, L. De Boni, E. Ishow and C. R. Mendonca, Sci. Rep., 2015, 4, 4447.

40 J. Herbich and A. Kapturkiewicz, J. Am. Chem. Soc., 1998, 120, 1014-1029.

${ }^{41}$ E. Lippert, Z. Naturforsch., 1955, 10a, 541-545.

42 a) P. Savel, H. Akdas-Kilig, J.-P. Malval, A. Spangenberg, T. Roisnel and J.-L. Fillaut, J. Mater. Chem. C, 2014, 2, 295-305; b) J.-P. Malval, F. Morlet-Savary, H. Chaumeil, L. Balan, D.-L. Versace, M. Jin and A. Defoin, J. Phys. Chem. C, 2009, 113, 20812-20821.

${ }^{43}$ M. G. Kuzyk, J. Chem. Phys. 2003, 119, 8327-8334. 